\title{
Nonabsorbable Suture Material in the Biliary Tract
}

\author{
Christian Beardsley • James Lim • \\ Sivakumar Gananadha
}

Received: 16 April 2012 /Accepted: 24 April 2012 / Published online: 10 May 2012

(C) 2012 The Society for Surgery of the Alimentary Tract

\begin{abstract}
Nonabsorbable sutures may act as a nidus for stone formation within the biliary tree. A case of a large stone formed as a consequence of a Prolene suture within the biliary tract is presented.
\end{abstract}

Keywords Gallstones · Biliary tract

\section{Case Report}

An 81-year-old female presented to the Emergency Department with intermittent episodes of epigastric pain over a month. This was associated with nausea and occasional vomiting. On examination, she was a frail thin lady with a palpable mass in the epigastrium. Her past medical history was significant in that she had an open cholecystectomy 51 years ago for cholelithiasis. She had presented 6 years ago with recurrent episodes of cholangitis, which on further investigations was found to be due to a large stone in the distal common bile duct. She underwent endoscopic retrograde cholangiopancreatography and insertion of a stent. Endoscopic stone extraction was unsuccessful on two separate occasions due to the size of the stone as well as

C. Beardsley $\cdot$ J. Lim $\cdot$ S. Gananadha

Upper GI/HPB Unit, Australian National

University Medical School, The Canberra Hospital,

Canberra, ACT 2605, Australia

S. Gananadha $(\bowtie)$

Department of Surgery, The Canberra Hospital,

Level 1, Building 6,

Garran, ACT 2605, Australia

e-mail: Sivakumar.Gananadha@act.gov.au difficulty in breaking it up with lithotripsy. The patient therefore had undergone a surgical extraction with a Roux-en-Y choledochojejunostomy reconstruction.

At the current admission, her blood tests revealed normal liver function tests. A CT scan of the abdomen showed a hyperdense mass in the epigastric region below the left lobe of the liver (Fig. 1). The appearance was suggestive of an intraluminal mass. The patient underwent a laparotomy at which time a large stone was found in the Roux limb. The stone was still attached to the bile duct by the suture (Fig. 2). The stone had not passed spontaneously due to the attachment to the biliary tree creating a ball-valve effect and causing intermittent symptoms over the previous month.

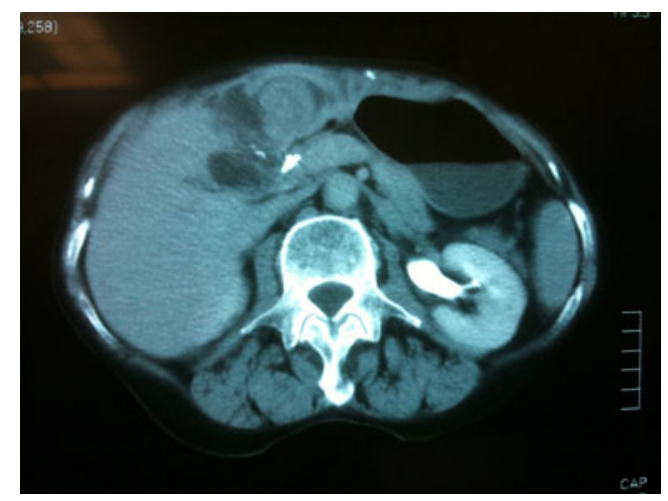

Fig. 1 CT scan of the abdomen showing a stone within the lumen of the Roux-en-Y limb 


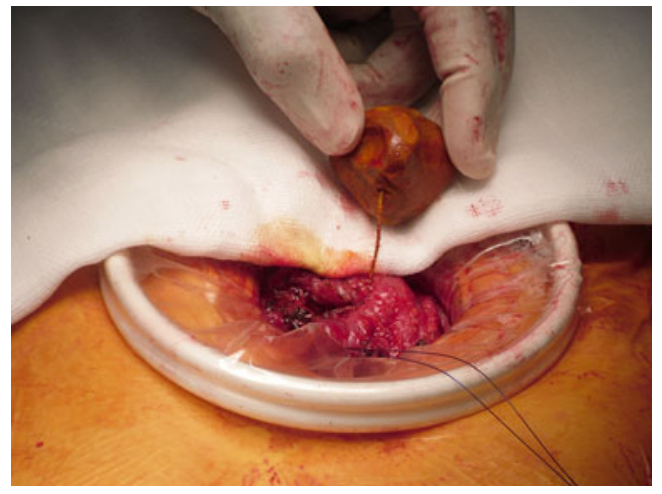

Fig. 2 Intraoperative picture showing the stone still attached by the Prolene suture to the biliary tract

A smaller stone was also found, which was in evolution along the suture material (Fig. 3). On macroscopic examination, a Prolene suture knot was seen to be the nucleus of the stone formation (Fig. 4). Her postoperative course was uneventful.

Suture material has long been known to act as a nidus for stone formation within the biliary tree since its first description by Homans in $1897 .{ }^{1}$ Nonabsorbable sutures particularly silk sutures are responsible for the majority of suture materialrelated stones in the literature. ${ }^{1-4}$ Nylon sutures have also been implicated in this phenomenon ${ }^{4,5}$ as have absorbable sutures such as chromic catgut. ${ }^{6}$ It has been postulated that the presence of suture material or other foreign bodies in the biliary tract leads to ongoing inflammation and biliary stasis. ${ }^{4}$ Calcium bilirubinate deposition around the nidus of the foreign body leads to eventual stone formation within the duct. ${ }^{3-5}$ Monofilament absorbable sutures seem to produce the least inflammatory response. ${ }^{7}$ With the advent of laparoscopic surgery, surgical clips have also been reported to cause stones,

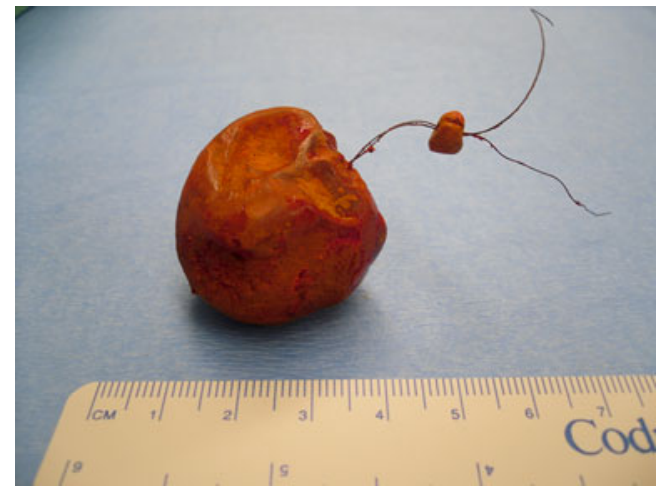

Fig. 3 The extracted stone with the Prolene suture

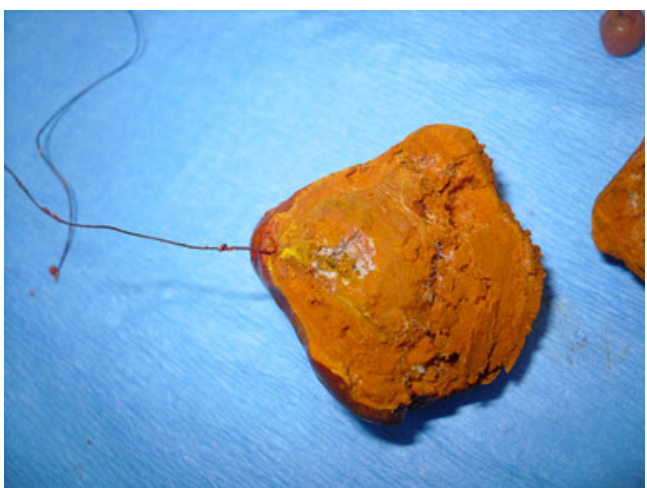

Fig. 4 The cut stone revealing the suture knot acting as a nidus

often due to migration of the clip from the cystic duct and into the common bile duct or hepatic ducts. ${ }^{2,3,8,9}$ Whilst the potential for secondary stone formation due to nonabsorbable suture material is rare, this interesting case demonstrates that it still warrants the use of absorbable suture material in the biliary tract structures.

\section{References}

1. Homans J. Gall-Stones formed around Silk Sutures Twenty Months after Recovery from Cholecystectomy. Ann Surg. 1897; 26 (1): 114-116

2. Fortun P, Anagnostopoulos G, Laurence B. Suture material as a nidus for common bile duct stones: taking a closer look. NZ med J. 2005; 118(1210): U1318.

3. Kook-Hyun K, Byung-Ik J, Tae-Nyeum K. A Common Bile Duct Stone formed by suture material after open cholecystectomy. Korean J Inter Med 2007; 22 (4): 279-282.

4. Kinoshita H, Sajima S, Hashino K, Hashimoto M, Sato S, Kawabata M, Tamae T, Hara M, Imayama H, Aoyagi S. A case of intrahepatic gallstone formation around nylon suture for hepatectomy. Kurume Med J. 2000; 47(3): 235-7.

5. Mackie B, Haynes S, May R. Unabsorbable Suture Material-A Rare cause of recurrent stones in the common bile duct. Brit J Surg 1973; 60 (1): 23-24.

6. Fink DL, Budd DC. Chromic suture material as a nidus for common duct stone formation. Int Surg. 1983;68:151-152.

7. Jeans P, Hall P, Liu YF, Baker RA, Holt A, Saccone GT, Harvey JR, Scicchitano J, Toouli J. Maxon is an optimal suture for bile duct anastomoses in pigs. HPB Surg. 1993;7(2):111-23; discussion $123-4$.

8. Martinez J, Wallace C, Brady P. Surgical Clips as a Nidus for Biliary Stone Formation: Diagnosis and Therapy. Am J Gastro 1995; 90 (9): $1521-1524$

9. Mansoa A, Martins A, Brito E, Melo M, Coito P. Surgical Clips as a nidus for stone formation in the common bile duct. Surg Endosc 2000; 14 (12): 1189 